\title{
Gastronomia e Sustentabilidade: uma análise da percepção da sustentabilidade ambiental em restaurantes buffet
}

\section{Food and Sustainability: an analysis of perception of environmental sustainability in buffet restaurants}

\section{Gastronomía y Sustentabilidad: un análisis de la percepción de la sostenibilidad ambiental en los restaurantes de buffet}

Laura Puntel ${ }^{1}$

Katarzyna Bortnowska Marinho

\section{Resumo}

O presente artigo abordou o tema sustentabilidade no setor gastronômico com o objetivo de analisar a percepção dos gestores de restaurantes buffet com relação às 'boas práticas' de sustentabilidade ambiental. Este assunto na Gastronomia envolve questões como agricultura, fornecedores e transporte, economia de recursos naturais e utilização de tecnologias limpas, procedimentos corretos para manipulação, porcionamento e produção dos alimentos, além da correta gestão dos resíduos produzidos. A aplicação de um questionário aos gestores de dezoito restaurantes da tipologia referida nos bairros Lagoa da Conceição e Rio Tavares em Florianópolis, demonstrou que $72 \%$ consideram que o restaurante causa algum tipo de impacto ambiental, enquanto $28 \%$ consideraram não impactar o meio ambiente de forma negativa, porém, mesmo entre os estabelecimentos que consideraram não causar impactos, alguma ação é realizada no sentido de minimizar os efeitos nocivos, resultando em $94 \%$ das respostas positivas na aderência a sustentabilidade. A importância da elaboração deste trabalho ocorreu no sentido de identificar as ações sustentáveis por meio da pesquisa bibliográfica e posterior análise da percepção dos gestores, bem como chamar a atenção para a relevância da execução das ações identificadas.

Palavras-chave: Sustentabilidade; Gastronomia; Restaurante sustentável; Florianópolis.

\begin{abstract}
This paper addressed the issue of sustainability in the gastronomic sector with the objective to analyze the perception of managers regarding the buffet restaurants 'best practices' of environmental sustainability. Gastronomy in this matter involves issues such as agriculture, and transportation providers, saving natural resources and use of clean technologies, to correct handling, portioning and food production procedures and the correct management of waste produced. The application of a questionnaire to managers of eighteen restaurants of the type referred at the neighborhoods of Lagoa da Conceição and Rio Tavares in

\footnotetext{
${ }^{1}$ Bacharel em Gastronomia pela Faculdade Estácio de Florianópolis. Brasil. E-mail: laurapuntel@ hotmail.com

${ }^{2}$ Professora do Curso de Gastronomia na Faculdade Estácio de Florianópolis e na Universidade do Sul de Santa Catarina (UNISUL). Mestre em Turismo e Hotelaria pela Universidade do Vale do Itajaí (UNIVALI).

Especialista em Gestão da Segurança de Alimentos pelo SENAC-SC. Brasil. E-mail:bortnowska@yahoo.com
} 
Florianópolis, showed that $72 \%$ considered the restaurant causes some kind of environmental impact, while $28 \%$ considered not impacting the environment negatively, but even among those considered not causing impacts, some action is performed in order to minimize adverse effects, resulting in $94 \%$ of responses. The significance of this development work was made towards the identification of sustainable actions through literature and the subsequent analysis of the managers perception survey, and draw attention to the importance of performing such actions.

Keywords: Sustainability; Gastronomy; Sustainable restaurant; Florianópolis.

\section{Resumen}

En este artículo se aborda el tema de la sostenibilidad en el sector gastronómico con el fin de analizar la percepción de los gerentes de los restaurantes buffet con respecto a la "buena práctica" de la sostenibilidad ambiental. Esto Gastronomía implica cuestiones como la agricultura, los proveedores y el transporte, la economía de los recursos naturales y el uso de tecnologías limpias, procedimientos correctos para la manipulación, fraccionamiento y la producción de alimentos, así como la gestión adecuada de los residuos generados. La aplicación de un cuestionario a los gerentes de dieciocho tipología de restaurantes citado en barrios Lagoa da Conceição Tavares y Rio en Florianópolis, mostró que el $72 \%$ considera que el restaurante porque algún tipo de impacto ambiental, mientras que el $28 \%$ no se considera afecta la manera a través de medio ambiente negativo, pero incluso entre los que se consideran no causar impactos, algún tipo de acción se lleva a cabo con el fin de minimizar los efectos nocivos, lo que resulta en $94 \%$ de las respuestas. La importancia de la elaboración de este trabajo se llevó a cabo hacia la identificación de acciones sostenibles a través de búsqueda bibliográfica y posterior análisis de la percepción de los directivos, así como llamar la atención sobre la importancia de llevar a cabo este tipo de acciones.

Palabras-clave: Sostenibilidad; Gastronomía; Restaurante sostenible; Florianópolis.

\section{Introdução}

A utilização indiscriminada dos recursos naturais, desde a obtenção das matérias-primas, dos processos de produção e serviços até a disposição final do produto após o uso, e os consequentes impactos negativos que isso causa ao meio ambiente, tem feito com que a sociedade se preocupe cada vez mais com a diminuição da qualidade e da quantidade dos recursos disponíveis na cadeia em que se vive (REIS; QUEIROZ, 2002). De acordo com Savitz e Weber (2007, p. 3):

Sustentabilidade é respeito à interdependência dos seres vivos entre si e em relação ao meio ambiente. Sustentabilidade significa operar a empresa, sem causar danos aos seres vivos e sem destruir o meio ambiente, mas, ao contrário, restaurando-o e enriquecendo-o. 
Em concordância a esta questão, Petrini (2009, p. 36-37) apresenta o argumento de que "o alimento e um estudo cuidadoso de como ele é produzido, comercializado e consumido é um elemento capaz de abrir nossos olhos para o que nos tornamos e para onde estamos indo [...] possibilitando-nos reconstruir as bases para um futuro sustentável".

A sustentabilidade em um restaurante envolve diversas questões além de simplesmente proporcionar uma alimentação saudável, está ligada a recomendações para agricultura, fornecedores, transporte e embalagens dos produtos até a chegada ao restaurante, inclui a normatização para procedimentos de manipulação, porcionamento e gestão dos resíduos produzidos, envolve o planejamento arquitetônico do local, a economia de energia e otimização na utilização dos recursos naturais (NUNES, 2012).

O objetivo deste trabalho é analisar a percepção dos gestores de restaurantes buffet com relação às 'boas práticas' de sustentabilidade ambiental, já que os restaurantes pertencentes a esta tipologia produzem diariamente grande quantidade de comida quando comparados à outras, estando assim, mais propícios a causar impactos ambientais como o desperdício de alimentos e a produção de lixo (AMORIM; JUNQUEIRA; JOKL, 2005). Para a realização desta análise, foi elaborado um estudo acerca dos tópicos e posteriormente, aplicado um questionário.

\section{Sustentabilidade Ambiental}

A sustentabilidade pode ser definida como todas as ações destinadas a manter as condições que sustentam a vida na terra, visando atender a continuidade e levando em consideração as necessidades das gerações presentes e das gerações futuras de uma forma que sejam mantidas a capacidade de regeneração, reprodução e coevolução dos recursos naturais (BOOF, 2012).

A sustentabilidade na Gastronomia requer atenção de gestores, organizadores e colaboradores para que possam haver significativas mudanças comportamentais, principalmente no que diz respeito a necessidade da redução de desperdícios de alimentos e produção de resíduos sólidos, tendo como decorrência posterior a redução dos custos (NERY et al, 2013).

O conceito do tripé da sustentabilidade, ou Triple Bottom Line, proposto originalmente na década de 1990, pelo analista britânico John Elkington, indica os três pilares que devem nortear a gestão sustentável nas empresas: social, econômico e ambiental (SAVITZ; WEBER, 
2007). Este modelo, também foi proposto por Coral (2002) em sua tese de doutorado e foi fundamentado com o objetivo de desenvolver um modelo de planejamento estratégico para o alcance da sustentabilidade empresarial, conforme Figura 1.

Figura - 1 Modelo de planejamento de estratégico para a sustentabilidade

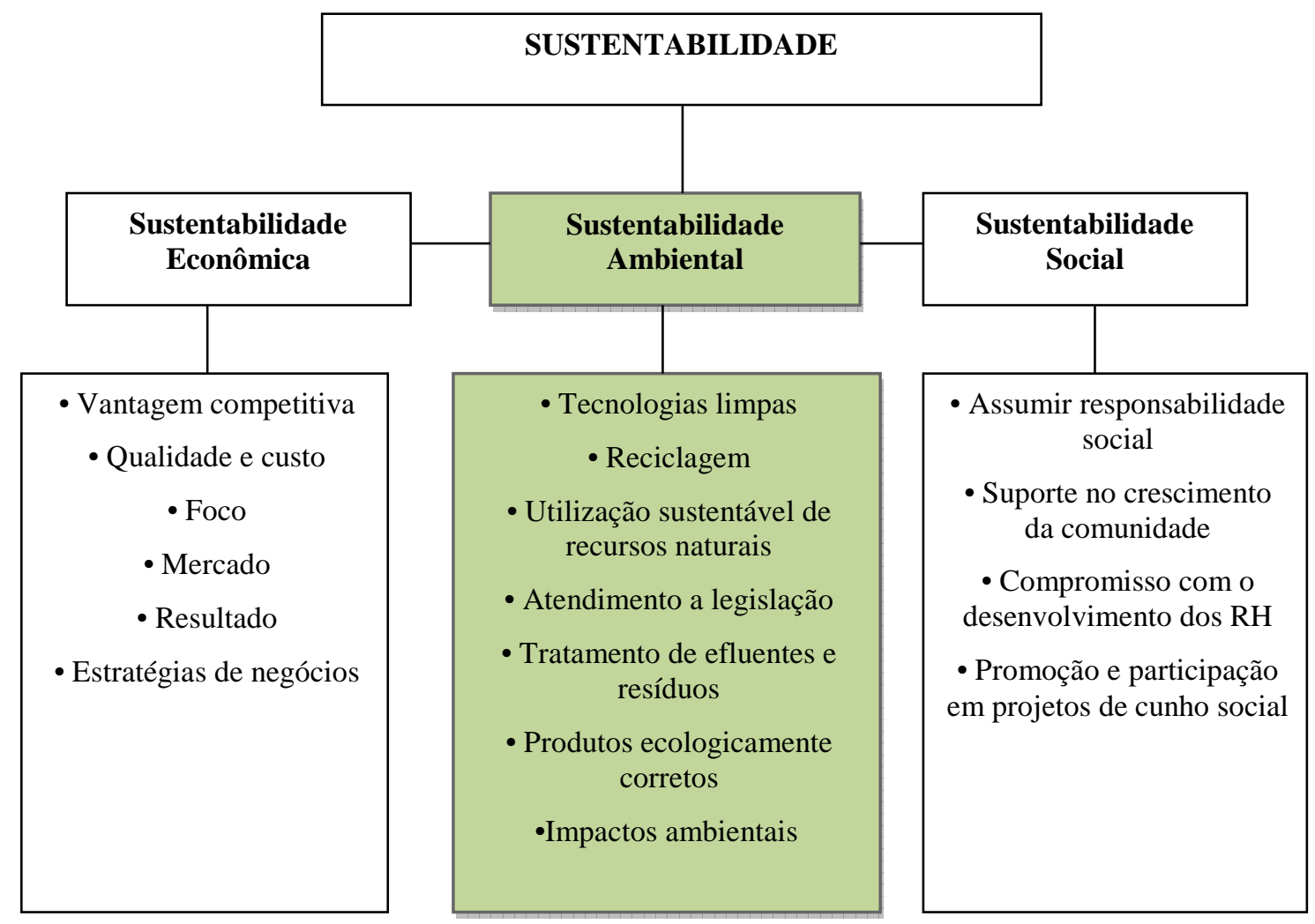

Fonte: Coral (2002, p. 129).

Nunes (2012) afirma que a gestão ambiental faz parte de um novo modelo de negócio, a Gastronomia Sustentável que pode obter resultados financeiros diminuindo os impactos que seus processos produtivos causam ao meio ambiente, melhorando a lucratividade e a imagem da marca para os clientes, já que o redesenho dos processos produtivos reduz o desperdício e o consumo dos recursos.

Os indicadores de sustentabilidade proposto pelo modelo de Coral (2002), estão de acordo ainda, com as atitudes propostas pela Sustainable Restaurant Association, uma organização sem fins lucrativos sediada no Reino Unido que ajuda os restaurantes a trabalharem de acordo com a sustentabilidade, além de orientar os consumidores para escolhas sustentáveis (THESRA, 2014, tradução nossa). 
A este propósito, o quadro abaixo apresenta os indicadores de sustentabilidade ambiental voltados para o segmento de alimentos e bebidas de acordo com a compreensão de alguns autores

Quadro 1 - Indicadores de sustentabilidade ambiental voltados para o segmento de alimentos e bebidas

\begin{tabular}{|c|c|}
\hline $\begin{array}{c}\text { Indicadores de Sustentabilidade } \\
\text { Ambiental }\end{array}$ & Autores e Ano \\
\hline $\begin{array}{l}\text { Utilização de tecnologias limpas e } \\
\text { uso consciente dos recursos } \\
\text { naturais. }\end{array}$ & $\begin{array}{l}\text { Venske (2001); Coral (2002); Faria, Gasparotto e Barbosa (2005); } \\
\text { Savitz e Weber (2007); Monforte (2007); Monteiro, Cianciardini e } \\
\text { Bruna (2004); Nunes (2012); Oliveira e Magalhães (2012); Solla e } \\
\text { Silva (2012); Rubim (2013); Thesra (2014); Dinegreen (2014). }\end{array}$ \\
\hline $\begin{array}{l}\text { Correta gestão e a redução dos } \\
\text { resíduos produzidos. }\end{array}$ & $\begin{array}{l}\text { Souza (2000); Coral (2002); Savitz e Weber (2007); Monforte } \\
\text { (2007); Blick et al (2008); Lafuente Junior (2012); Nunes (2012); } \\
\text { Rita et al (2012); Solla e Silva (2012); Bochnia et al (2013); Nery } \\
\text { et al (2013); Peruchin et al (2013); Rubim (2013); Santos et al } \\
\text { (2013); Amaral et al (2014); Thesra (2014); Dinegreen (2014). }\end{array}$ \\
\hline $\begin{array}{l}\text { Consumo consciente através dos } \\
\text { fornecedores e da cadeia de } \\
\text { mantimentos ecologicamente } \\
\text { correta. }\end{array}$ & $\begin{array}{l}\text { Coral (2002); Monforte (2007); Singer e Mason (2007); Cristóvão } \\
\text { e Tibério (2008); Nunes (2012); Solla e Silva (2012); Krause e } \\
\text { Bahls (2013); Puiatti et al (2013); Rubim (2013); Thesra (2014); } \\
\text { Dinegreen (2014). }\end{array}$ \\
\hline Valorização da agricultura local. & $\begin{array}{l}\text { Archanjo, Brito e Sauerbeck (2001); Monforte (2007); Singer e } \\
\text { Mason (2007); Cristóvão e Tibério (2008); Zuin e Zuin (2008); } \\
\text { Nunes (2012); Rita et al (2012); Solla e Silva (2012); Souza, } \\
\text { Carvalho e Bartholo Júnior (2012); Serrão, Almeida e Carestiato } \\
\text { (2012); Bôas (2013) Rubim (2013); Thesra (2014); Dinegreen } \\
\text { (2014). }\end{array}$ \\
\hline $\begin{array}{l}\text { Otimização e o reaproveitamento } \\
\text { de produtos. }\end{array}$ & $\begin{array}{l}\text { Monforte (2007); Blick et al (2008); Serrão, Almeida e Carestiato } \\
\text { (2012); Nery et al (2013); Rubim (2013); Silvério e Oltramari } \\
\text { (2014); Thesra (2014); Dinegreen (2014). }\end{array}$ \\
\hline $\begin{array}{c}\text { Atendimento às legislações } \\
\text { vigentes e certificação ambiental. }\end{array}$ & Coral (2002); Monteiro, Cianciardini e Bruna (2004). \\
\hline
\end{tabular}

Fonte: Elaborado pelas autoras. 2015.

Desta forma, foi possível verificar a existência de vários estudos que refletem a importância da sustentabilidade ambiental em relação a diversos aspectos, desde a preocupação com as formas de produção e fornecimento até o consumo consciente e a responsabilidade perante os resíduos produzidos.

\subsection{Utilização de tecnologias limpas e uso consciente de recursos naturais}

Os recursos naturais que atuam diretamente sobre o local, como sol, vento e vegetação podem ser utilizados para obtenção de iluminação, conforto termo-acústico e climatização natural. A eficiência energética pode ser alcançada em partes através da instalação de placas 
fotovoltaicas ${ }^{3}$ para captação de energia solar e utilização na alimentação do sistema de iluminação e aquecimento de água, telhas translúcidas garantem a iluminação natural durante o dia e a instalação de circuitos de baixa voltagem para utilização de lâmpadas LED 4 garante um consumo de energia consideravelmente inferior e uma durabilidade superior em comparação às lâmpadas comuns, além disso, essas lâmpadas não contém metais pesados em seu interior, o que facilita o descarte após o uso (OLIVEIRA; MAGALHÃES, 2012).

Um estudo realizado por Barbosa et al (2007b) avaliou os benefícios da implantação de placas fotovoltaicas para a captação de energia solar em um restaurante localizado as margens do Rio São Francisco, no nordeste brasileiro, com objetivo de utilização na iluminação, em refrigeradores, freezers e outros aparelhos domésticos. Após a implantação, as análises revelaram um aumento de renda mensal de $145 \%$ para os proprietários, o número de pessoas diretamente beneficiadas duplicou e o atendimento aos clientes aumentou em média $450 \%$ no período de alta estação, comprovando assim, além dos benefícios ambientais, os benefícios econômicos da implantação e utilização da energia solar.

Outro estudo realizado por Faria, Gasparotto e Barbosa (2005) sobre a economia de energia em um restaurante universitário através do aquecimento solar da água, comprovou que se ao invés de ser aquecida pelo método tradicional utilizado (caldeira movida a combustível) a água fosse aquecida através do calor produzido por placas solares, seria possível uma economia de $8,1 \%$ com gasto de combustíveis e consequentemente a mesma diminuição de poluição através do uso de óleo diesel para aquecer as caldeiras. Os autores afirmam ainda, que o custo de manutenção das placas solares, é praticamente nulo, o que possibilitaria uma economia mensal considerável viabilizando o pagamento da implantação do sistema solar num período de dois a três anos, barateando ainda o custo final das refeições e sendo ecologicamente e economicamente viável para implantação no referido restaurante.

O uso racional da água no setor de alimentação objetiva a otimização durante os processos que necessitam da sua utilização, como nas etapas de higienização, manipulação de alimentos e lavagem de equipamentos e utensílios (SOLLA; SILVA, 2012), deve ser adotado com o objetivo de reduzir o consumo e estimular que novas atitudes e comportamentos sejam incorporados por todos os envolvidos nos processos. Para uma melhor efetivação da

\footnotetext{
${ }^{3}$ Painéis para captação de energia solar, fonte inesgotável e não poluente (MARINOSKI; SALAMONI; RÜTHER, 2004).

${ }^{4}$ Diodos emissores de luz, dispositivos condutores de energia (PINTO, 2008).
} 
diminuição do desperdício e do volume de água utilizado devem ser realizadas ações sociais no sentido de conscientizar a equipe de funcionários promovendo uma mudança no comportamento individual de todos os envolvidos, além do desenvolvimento de algumas ações aliadas a tecnologia, como substituir sistemas convencionais de abastecimento por economizadores de água, implantar sistemas de medição em cada setor, detectar e corrigir eventuais vazamentos, além de reaproveitar e reciclar a água servida (OLIVEIRA; GONÇALVES, 1999; MONTEIRO; CIANCIARDINI; BRUNA, 2004).

Monteiro, Cianciardini e Bruna (2004) ainda indicam alguns equipamentos que ajudam a reduzir o consumo de água nos estabelecimentos de alimentação profissional, como torneiras acionadas por pedais com fluxo controlado pelos pés, torneiras com bocais dotados de chuveiros dispersantes que chegam até a metade da cuba da pia contribuindo para o aumento do contato da água com os utensílios que estão sendo lavados, reduzindo em até $50 \%$ o consumo em relação as torneiras tradicionais e lavadoras de louça automáticas que utilizam um sistema com um tanque de acumulação e chegam a reduzir de 50 a $90 \%$ o consumo de água em relação a lavagem manual.

\subsection{Correta gestão e a redução de resíduos produzidos}

O descarte adequado do lixo produzido tem se tornado um fator de suma importância para a sobrevivência do planeta e para que seja possível manter a qualidade de vida daqueles que habitam o meio, porém, as desigualdades sociais, o crescimento acelerado da população e a concentração econômica colaboram para o aumento do consumo, e consequentemente, para o aumento da produção de lixo, contaminando o solo, a água e o ar, causando danos a flora, a fauna e se tornando uma ameaça à manutenção da saúde pública (AMARAL et al, 2014).

No Brasil, grande parte dos resíduos sólidos tem como destino final os lixões e em menor parte, os aterros sanitários, que são aqueles que possuem algum tipo de tratamento. Souza (2000, p. 14) chama a atenção de que:

O reaproveitamento ou a disposição correta desses resíduos envolve aspectos sociais, econômicos e ecológicos e um novo comportamento individual deve pautar a mudança de valores e o padrão de consumo sustentável, repensando a minimização e a conscientização de desejos materiais.

Prevista para entrar em vigor a partir de 2015, a nova Política Nacional de Resíduos Sólidos (PNRS) - Lei 12305/2010, determina que não seja mais permitido o uso de lixões pelos municípios para depósito dos detritos, apenas de aterros sanitários legalizados que deverão 
receber somente rejeitos, aqueles materiais que não podem ser reciclados ou reaproveitados e do qual já foram esgotadas todas as possibilidades de tratamento e recuperação. Essa lei prevê ainda, que a responsabilidade do destino do lixo é de todos os envolvidos que fazem parte do ciclo de vida do produto, sejam eles consumidores, fabricantes, distribuidores ou comerciantes e estabelece que a gestão dos resíduos deve ser priorizada na ordem de não geração, redução, reutilização, reciclagem, tratamento dos resíduos sólidos e disposição final ambientalmente adequada dos rejeitos (NERY et al, 2013; ABREU, 2013; AMARAL et al, 2014).

A prática sustentável conhecida como 3 R's (Reduzir, Reutilizar e Reciclar) é uma metodologia eficiente capaz de contribuir para não esgotar a capacidade dos aterros sanitários, tem se tornado imprescindível para a preservação dos recursos naturais e para que seja possível manter um modo de vida saudável e responsável. Reduzir consiste em evitar a produção de resíduos, reavaliando os hábitos de consumo e reduzindo o uso de matériasprimas, energia e geração de lixo, reutilizar envolve o reaproveitamento dos materiais em outras funções do cotidiano e reciclar significa transformar materiais já usados em novos produtos (SANTOS; AGNELLI; MANRICH, 2004; LOCATELLI; SANCHEZ; ALMEIDA, 2008;).

Lafuente Junior (2012) indica os principais benefícios ambientais da reciclagem dos resíduos sólidos, entre eles estão a economia de matérias-primas não renováveis, a economia de energia nos processos produtivos e o aumento da vida útil dos aterros sanitários.

Amaral et al (2014, p. 2) fundamenta esta questão no setor gastronômico considerando que:

[...] restaurantes e cozinhas industriais, ao realizarem o preparo dos alimentos, geram grande quantidade de resíduos sólidos, e de forma acentuada, o resíduo orgânico, sendo este passível de transformação e reaproveitamento em outros fins. Nota-se que o restaurante apresenta-se como um elo fundamental na cadeia produtiva, tendo como consequências; não apenas no sentido econômico, mas também no ambiental.

No setor gastronômico, o escoamento dos resíduos líquidos (efluentes) deve ser feito através do sistema de esgotamento sanitário (ACRE; CASTILHO, 2013), ainda se faz necessário o uso de outras técnicas para o descarte adequado do lixo orgânico e do óleo de cozinha. A alternativa mais viável para o destino do lixo orgânico, composto por restos de alimentos, cascas de legumes e frutas é a compostagem, este método consiste na transformação natural dos resíduos sólidos orgânicos em um fertilizante de ótima qualidade e economicamente 
viável (VENZKE，2001; MONTEIRO; CIANCIARDINI; BRUNA，2004; LAFUENTE JUNIOR, 2012). Em concordância a esta indicação, Abreu (2013, p. 34) considera que:

Em termos de contribuição ambiental, com o tratamento de resíduos orgânicos através da compostagem realiza-se a ciclagem de nutrientes contribuindo para o retorno do fluxo energético e de fertilidade aos agro ecossistemas que produziram os alimentos, através do composto orgânico.

Um estudo realizado por Peruchin et al (2013) aponta que cerca de $80 \%$ dos resíduos produzidos em um restaurante são provenientes de matéria orgânica, seguidos em menores quantidades por plásticos, papéis ou papelão e outros, o mais indicado também por estes autores é que esse montante de resíduos orgânicos seja destinado para compostagem.

Sendo assim, a compostagem dos resíduos sólidos e a utilização do fertilizante para o cultivo de hortaliças, além de serem ações ecologicamente corretas que contribuem para a redução do acúmulo de resíduos sólidos dos aterros sanitários, são de suma importância para o desenvolvimento da sustentabilidade ambiental, econômica e social (BLICK et al, 2008; BOCHNIA et al, 2013).

Já a indicação mais adequada para o óleo de cozinha é que ele seja armazenado após ser resfriado e enviado para empresas ou entidades que realizem sua reciclagem, a opção mais adequada é a transformação em biocombustível (BLICK et al, 2008; SCHNEIDER et al, 2009; FREITAS; BARATA; MOREIRA NETO, 2010;), outra alternativa viável, porém menos indicada por conter outros poluentes em sua fabricação é a produção de sabão (BLICK et al, 2008).

Na cidade de Florianópolis, a ACIF (Associação Comercial e Industrial) mantém desde 1998 o Programa Reóleo que consiste em captar o óleo gerado pelos restaurantes associados e encaminhá-lo para reciclagem. A iniciativa surgiu após estudos comprovarem o entupimento do sistema de esgoto da orla da Lagoa da Conceição, ocasionado pelo descarte indevido do óleo de cozinha, desde então, o projeto tem crescido e realiza também a captação do óleo de uso doméstico, além de inúmeras atividades de educação ambiental envolvendo toda a comunidade (ACIF, 2014).

No segmento de alimentos e bebidas outras ações específicas ainda podem ser realizadas para evitar o excesso da geração de resíduos, como diminuir o uso excessivo de embalagens, dar 
preferência para a utilização de materiais permanentes ao invés de descartáveis ou se necessário utilizar os que possam ser reciclados (SOUZA, 2000; SOLLA; SILVA, 2012).

\subsection{Consumo consciente através dos fornecedores e da cadeia de mantimentos ecologicamente correta}

Para que um restaurante seja considerado ecologicamente responsável, a seleção dos fornecedores deve se basear não apenas no preço e na qualidade dos produtos, também é preciso que os gestores optem por aqueles que demonstrem ter responsabilidade tanto em relação à sociedade, quanto ao meio ambiente (NUNES, 2012), já que este sofre impacto direto causado pela produção e transporte de alimentos.

São considerados ecologicamente responsáveis os fornecedores que respeitam seus colaboradores, as leis ambientais e trabalhistas e cumprem com as obrigações legais, não comercializam produtos em risco de extinção, utilizam embalagens retorrnáveis, recicláveis ou biodegradáveis, comercializam alimentos sazonais e da própria região, trabalham com agricultura sustentável e realizam a gestão adequada de seus resíduos, além de priorizarem uma estrutura física que permita a otimização da utilização dos recursos naturais na fabricação de seus produtos (PUIATTI et al, 2013).

Além disso, quando possível, a preferência por alimentos locais é vista como a melhor alternativa relacionada à diminuição dos impactos ambientais, além de serem mais frescos e de melhor qualidade do que os alimentos que percorrem longas distâncias, essa opção proporciona uma significativa diminuição nos custos e na emissão de poluentes, que são decorrências inevitáveis do transporte (SINGER; MASON, 2007; CRISTÓVÃO; TIBÉRIO, 2008; KRAUSE; BAHLS, 2013; PUIATTI et al, 2013). Ainda é importante ressaltar que a correta embalagem e estocagem dos alimentos são fatores fundamentais para aumentar a validade e a qualidade dos mesmos, diminuindo assim o desperdício e os impactos ao meio ambiente causados pelo uso indevido dos recursos naturais (KRAUSE; BAHLS, 2013).

\subsection{Valorização da agricultura local}

As críticas ao atual modelo de agricultura vigente tem aumentado consideravelmente a medida que estudos comprovam os efeitos negativos que o uso de agrotóxicos causa à saúde e ao meio ambiente. Como consequência, tem ocorrido um aumento pela procura de alimentos orgânicos, livres de fertilizantes químicos, antibióticos e hormônios que são utilizados em 
larga escala na agricultura industrial (ARCHANJO; BRITO; SAUERBECK, 2001; ZUIN; ZUIN, 2008).

Neste sentido, na Gastronomia a busca por proporcionar uma alimentação saudável aos clientes, respeitando a sazonalidade, dando preferência aos produtos sem a utilização de agrotóxicos em seu cultivo e advindos da agricultura familiar fortalece a sustentabilidade ambiental ao mesmo tempo em que contempla o fortalecimento social sem deixar de ser economicamente viável (RITA et al, 2012). A lei $\mathrm{n}^{\circ} 11.326$ de 24 de julho de 2006, prevê como agricultura familiar aquela que desenvolve suas atividades no meio rural, utilizando de preferência, a mão de obra da própria família nas suas atividades econômicas (SOLLA; SILVA, 2012).

Como se pode observar, a preferência por produtos regionais e a valorização da agricultura local são práticas condizentes com a questão da sustentabilidade, pois fortalecem a economia da região e favorecem os pequenos produtores trazendo desenvolvimento para a região ao mesmo tempo em que colaboram para a proteção do meio ambiente (ARCHANJO; BRITO; SAUERBECK, 2001; SINGER; MASON, 2007; BÔAS, 2013).

Ao contrário do exposto, a agricultura industrial além de trazer consequências ambientais como poluição da água, do ar e do solo, desgaste e empobrecimento do solo, desmatamento, contaminação de áreas periféricas, entre outros, também traz consequências sociais, como o êxodo rural, perda das características culturais do homem do campo e extinção das técnicas tradicionais de cultivo, e ainda, consequências econômicas, como subemprego e trabalhadores rurais mal pagos, concorrência desleal e pequenos produtores que não sobrevivem frente as grandes empresas donas de sementes, fertilizantes e pesticidas que dominam o mercado atual (RUBIM, 2013).

\subsection{Otimização e reaproveitamento de produtos}

O reaproveitamento de produtos e a reintrodução de subprodutos na cadeia produtiva de alimentos pode vir a ser no futuro, a garantia de equilíbrio econômico, social e ambiental (BLICK et al, 2008). O desperdício ocorre em todas as etapas da cadeia alimentar, abrangendo os processos de produção, transporte, comercialização, embalagem e armazenamento (SILVÉRIO; OLTRAMARI, 2014).

Em uma unidade produtora de alimentos é importante considerar duas nomenclaturas utilizadas para diferenciar os objetos de descarte, são as sobras e os restos. As sobras são 
provenientes de preparações que não foram oferecidas para consumo, enquanto os restos já foram expostos e rejeitados após as pessoas se servirem e não são mais passíveis de reutilização (SILVÉRIO; OLTRAMARI, 2014).

Neste sentido, Krause e Bahls (2013) consideram que o desperdício de alimentos deve ser analisado em dois momentos, no pré e no pós-consumo. Os resíduos de pré-consumo são os que não serviram para ir aos pratos dos clientes, decorrentes geralmente da baixa qualidade dos ingredientes desde o momento da compra ou da falta de cuidado durante a estocagem, o que acaba por levá-los ao descarte, a principal ação para diminuir este desperdício é evitar o excessos nas compras e observar um maior cuidado durante o estoque. Já uma alternativa para evitar o desperdício pós-consumo, é o dimensionamento adequado das porções, o que além de diminuir a quantidade de resíduos produzidos, otimiza a utilização dos recursos gerando maior rentabilidade para o estabelecimento (KRAUSE; BAHLS, 2013).

Com relação à otimização dos ingredientes e também à diminuição do desperdício, Nery et al (2013, p. 270) chama a atenção de que:

Apesar dos variados aspectos técnicos inerentes a cocção e a produção de alimentos em meios coletivos, deve-se avaliar a possibilidade de aproveitamento do alimento em todas as suas fases, da elaboração ao consumo. Trata-se de um elemento fundamental nos dias atuais tanto pelo seu valor nutritivo, ambiental e social, como por representar custos que podem ser reduzidos.

Os restos podem ser totalmente aproveitados através de diferentes formas de utilização, o mais indicado é a compostagem ou a destinação para alimentação de animais. Já as sobras, podem ser utilizadas no preparo de outros pratos, diversificando o cardápio, ou encaminhadas para doação, desde que sejam observadas as normas de segurança alimentar e estejam em perfeito estado de conservação, porém, diariamente, muitas toneladas são enviadas para o lixo, já que as empresas não querem arcar com o ônus dos processos de redistribuição (BLICK et al, 2008).

Mesmo com os desafios impostos pela logística de redistribuição para consumo humano, o Serviço Social do Comércio (SESC) mantém o projeto Mesa Brasil, que é um exemplo da doação de alimentos próprios para o consumo porém fora dos padrões de comercialização. Este projeto foi criado em 2003 e hoje já está presente em todos os estados do país, consiste em recolher alimentos provenientes de restaurantes, redes de supermercado, associações de produtores rurais e estabelecimentos comerciais entre outros, após a recolha, os alimentos 
passam por uma segunda triagem e são mantidos de acordo com suas necessidades de conservação para então serem distribuídos para as entidades beneficiadas (SERRÃO; ALMEIDA; CARESTIATO, 2012).

Apesar da legislação brasileira inibir essa prática através do decreto lei $n^{\circ} 2.848$ de 1940 que responsabiliza integralmente os doadores por eventuais danos causados à saúde de quem consome os alimentos doados (SILVÉRIO; OLTRAMARI, 2014), já existe o projeto de lei $\mathrm{n}^{\circ} 102$ de 2012 que foi aprovado pelo senado e aguarda a votação na câmara dos deputados, ele prevê um novo conjunto de regras para a doação de sobras de alimentos em boas condições de consumo, evitando assim que toneladas de comida sejam desperdiçadas diariamente (BRASIL, 2014).

\subsection{Atendimento às legislações vigentes e certificação ambiental}

A Agência Nacional de Vigilância Sanitária (ANVISA), dentro das regulamentações e leis destinadas aos segmentos de alimentos e bebidas prevê, com relação aos resíduos produzidos, que devem haver recipientes íntegros, identificados, de fácil higienização e transporte, suficientemente capazes de contê-los. Estes resíduos devem ser estocados em um local fechado e isolado da área de preparação e armazenamento de alimentos, evitando a possibilidade de contaminações e atração de vetores e pragas urbanas. Os coletores das áreas de preparação e produção ainda devem ser dotados de tampas acionadas sem a necessidade de contato manual (ANVISA, 2014).

Ainda não há uma legislação específica sobre as questões que envolvem a sustentabilidade no segmento de unidades produtoras de alimentos, porém já existe uma série de certificações que visam nortear as práticas sustentáveis empresariais. A série de certificações ISO 14000 é um conjunto de normas na área de gestão ambiental que visa padronizar procedimentos e diretrizes básicas para a gestão ambiental dentro das empresas (COSTA; PEREIRA; CAMELO, 2007).

Na Gastronomia, a ISO 14001 fundamenta sistemas e processos de restaurantes através da certificação de 'cozinhas verdes', diversas experiências já demonstraram reduções significativas dos custos finais do estabelecimento após a implantação de ações para reduzir o consumo de água, energia elétrica, geração de lixo e coleta seletiva. $\mathrm{O}$ alcance de serviços de alimentação autossustentáveis se tornará o grande desafio dessa e das futuras gerações em benefício da preservação ambiental, as buscas por certificações auxiliam neste sentido 
norteando ações e indicando os melhores caminhos a serem seguidos em prol das empresas e do meio ambiente (MONTEIRO; CIANCIARDINI; BRUNA, 2004

\section{Metodologia}

Trata-se de uma pesquisa exploratória e descritiva. A pesquisa exploratória tem por objetivo conhecer a variável de estudo tal como se apresenta, seu significado e o contexto onde ela se insere (QUEIRÓZ, 1992).

Com o resultado da pesquisa exploratória foi possível identificar o modelo de Coral (2002) para realizar a fase descritiva, ou seja, levantar os indicadores de sustentabilidade ambiental e as ações a serem realizadas pelas empresas do setor gastronômico. Não foram considerados os indicadores de sustentabilidade econômica e social propostos pelo modelo, já que o foco do trabalho consiste em observar os impactos que as atividades produtivas de um restaurante causam ao meio ambiente, além do que pode ser feito para minimizar estes impactos.

Foi um estudo em corte transversal, no qual segundo Hoppen; Lapointe e Moreau (1996) o pesquisador deve coletar os dados da amostra que sejam suficientes para retratar as variáveis em um determinado momento no tempo. A amostra da pesquisa foi obtida de forma não probabilística por julgamento que ocorre quando a escolha da amostra ocorre por conveniência com base no julgamento ou experiência do pesquisador, pois os consideram representativos da população de interesse ou apropriados por qualquer outro motivo (MALHOTRA, 2001).

A análise dos resultados ocorreu de forma quantitativa por meio da aplicação de questionário aos gestores de dezoito restaurantes localizados nos bairros da Lagoa da Conceição e Rio Tavares em Florianópolis.

Foram escolhidos os restaurantes buffet de tipologia self-service que são considerados uma tendência atual e estão mais suscetíveis a gerar desperdícios, pois produzem diariamente uma grande quantidade de comida (AMORIM; JUNQUEIRA; JOKL, 2005) e assim mais propensos a causar impactos ambientais. De acordo com Zanella (2007) o self-service é um sistema de serviço rápido, onde as preparações ficam dispostas e o cliente se serve, pode ser praticado em duas modalidades, buffet por quilo, ou buffet livre (com preço fixo), é um serviço comum e bastante apreciado, pois permite que o próprio cliente se sirva sem a 
intervenção de outras pessoas, geralmente possui preços acessíveis e é atrativo visualmente pelas variadas opções de pratos disponíveis.

\section{Análise dos Resultados}

Neste tópico são apresentados os resultados referente aos questionários aplicados aos dezoito gestores dos restaurantes buffet situados em dois bairros de Florianópolis. O questionamento inicial tinha como objetivo verificar se os gestores consideravam que o restaurante, sob sua supervisão, causava algum tipo de impacto ambiental, um total de $72 \%$ dos entrevistados considerou que o restaurante causava algum tipo de impacto ambiental, enquanto $28 \%$ consideraram não causar nenhum impacto. Em caso de resposta positiva, foram apresentadas afirmativas sobre quais seriam estes impactos, demonstradas de acordo com o Gráfico 1.

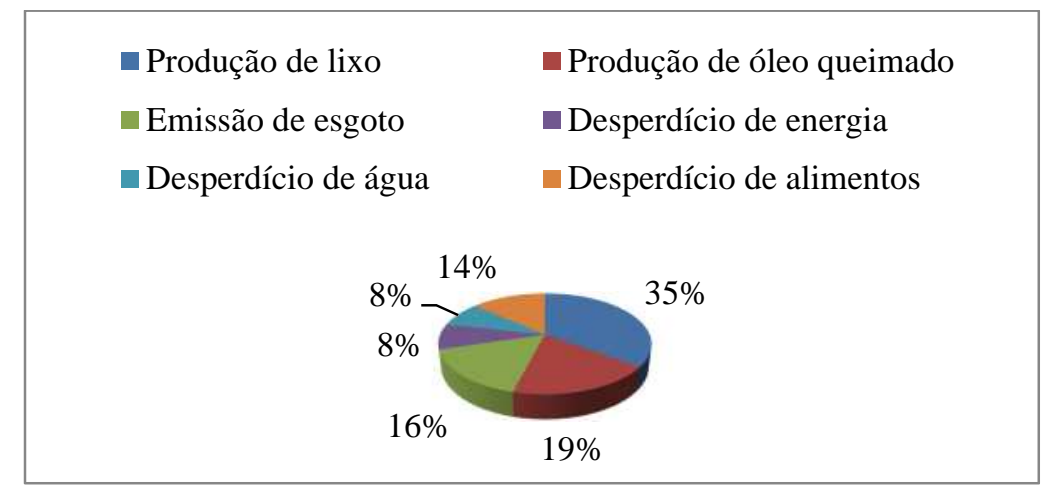

Gráfico 1 - Quais impactos são causados

Fonte: Elaborado pelas autoras. 2015.

Com relação a questão dos impactos ambientais causados pelos restaurantes, $35 \%$ dos gestores responderam a alternativa que indicava a "produção de lixo", este resultado está de acordo com Venske (2001) que aponta esta como a principal causa de impactos ambientais decorrentes dos processos produtivos dos restaurantes. Além disso, os gestores indicaram os seguintes impactos: 19\% a produção de óleo de cozinha queimado, 16\% a emissão de esgoto, 14\% o desperdício de alimentos, $8 \%$ o desperdício de água e $8 \%$ o desperdício de energia.

Foi possível perceber que a maioria dos gestores considerou causar algum tipo de impacto ambiental e mesmo os que consideraram não impactar o meio ambiente realizam alguma ação de minimização destes efeitos nocivos, o que foi demonstrado na resposta do questionamento sobre a realização (ou não) de alguma ação para diminuir impactos. 
A maioria dos gestores afirmou realizar alguma ação para diminuir os impactos ambientais ocasionados pelo restaurante, totalizando $94 \%$, enquanto $6 \%$ não realizam nenhuma ação neste sentido, o que demonstra uma boa adesão às práticas sustentáveis por parte dos restaurantes. Isso se deve, além da diminuição dos recursos, ao fato de que nas últimas décadas, as empresas passaram a ser responsáveis não apenas pelo que produzem, mas também por seus fornecedores, pela comunidade em que atuam e pelas pessoas que usam seus produtos ou consomem seus serviços, o que faz com que a sustentabilidade seja considerada mais importante hoje do que em outras épocas (SAVITZ; WEBER, 2007).

Mediante a resposta afirmativa sobre a realização de ações para diminuir os impactos ambientais, foram questionados sobre quais seriam as ações realizadas pelo restaurante, com opção também de incluírem outras respostas além das alternativas sugeridas pelas autoras, demonstradas a seguir no Quadro 2.

Quadro 2 - Quais ações são realizadas para diminuir os impactos ambientais

\begin{tabular}{|c|c|}
\hline TÓPICOS & $\%$ \\
\hline Destinação e descarte correto do óleo de cozinha queimado & $15 \%$ \\
\hline Separação e destinação dos resíduos sólidos para reciclagem & $11 \%$ \\
\hline Redução do desperdício de alimentos & $11 \%$ \\
\hline Economia de água & $11 \%$ \\
\hline Economia de energia & $11 \%$ \\
\hline Separação e destinação dos resíduos orgânicos para compostagem & $06 \%$ \\
\hline Diminuição da utilização de produtos químicos de limpeza ou substituição por produtos biodegradáveis & $06 \%$ \\
\hline Utilização integral dos alimentos & $05 \%$ \\
\hline Redução da utilização de embalagens descartáveis & $05 \%$ \\
\hline Compra de insumos locais & $05 \%$ \\
\hline Economia do gás de cozinha & $04 \%$ \\
\hline Preferência por fornecedores ecologicamente corretos & $04 \%$ \\
\hline Reuterentilização de água da chuva & $02 \%$ \\
\hline Produção de sabão com óleo usado em substituição aos detergentes & $01 \%$ \\
\hline Cultivo de horta própria orgânica para utilização do restaurante & $01 \%$ \\
\hline & $01 \%$ \\
\hline
\end{tabular}

Fonte: Elaborado pelas autoras. 2015.

De acordo com o Quadro 2, as respostas sobre a realização de ações sustentáveis tiveram como destaque a destinação e descarte correto do óleo de cozinha queimado, realizado em $15 \%$ dos estabelecimentos, decorrente provavelmente do apoio proporcionado aos restaurantes pela Associação Comercial e Industrial de Florianópolis (ACIF) para captação e destino correto deste resíduo, seguido de $11 \%$ pela separação e destinação dos resíduos sólidos para reciclagem, assim como a redução do desperdício de alimentos, economia de água e economia de energia, cada um destes igualmente com $11 \%$ das respostas. 
Este resultado está alinhado a pesquisa de Kremer, Costa e Mondo (2013) que mostra que os gestores consideram importante a responsabilidade ambiental, em que $82 \%$ dos restaurantes realizam medidas/ações sustentáveis em relação ao meio ambiente, tais como: 85,7\% realizam a destinação do óleo utilizado para a coleta especializada; $77,1 \%$, buscam a redução de desperdício de alimentos e empatados com $74,3 \%$ a inserção da coleta seletiva de lixo e cuidados com o esgoto. Pospischek, Spinelli e Matias (2014) reforçam que existe necessidade da conscientização de todos os indivíduos inseridos nas unidades de alimentação para que haja efetividade do sistema de gestão ambiental.

Nenhum restaurante citou a utilização de energia solar em substituição a energia elétrica, demonstrando que o setor ainda é carente no que diz respeito a utilização de energias renováveis, como considera Barbosa et al (2007a) já que a utilização de energia elétrica ou de combustíveis fósseis tem um valor mais acessível do que as instalações necessárias para captação de energia solar, porém, é importante ressaltar que um estudo realizado por Faria, Gasparotto e Barbosa (2005) comprovou além dos benefícios ambientais, os benefícios econômicos que ocorrem a médio e longo prazo após a implantação dos sistemas para captação desta energia alternativa.

O Gráfico 2 demonstra quais seriam os motivos que levam os restaurantes a incluir práticas de ações sustentáveis em suas rotinas.

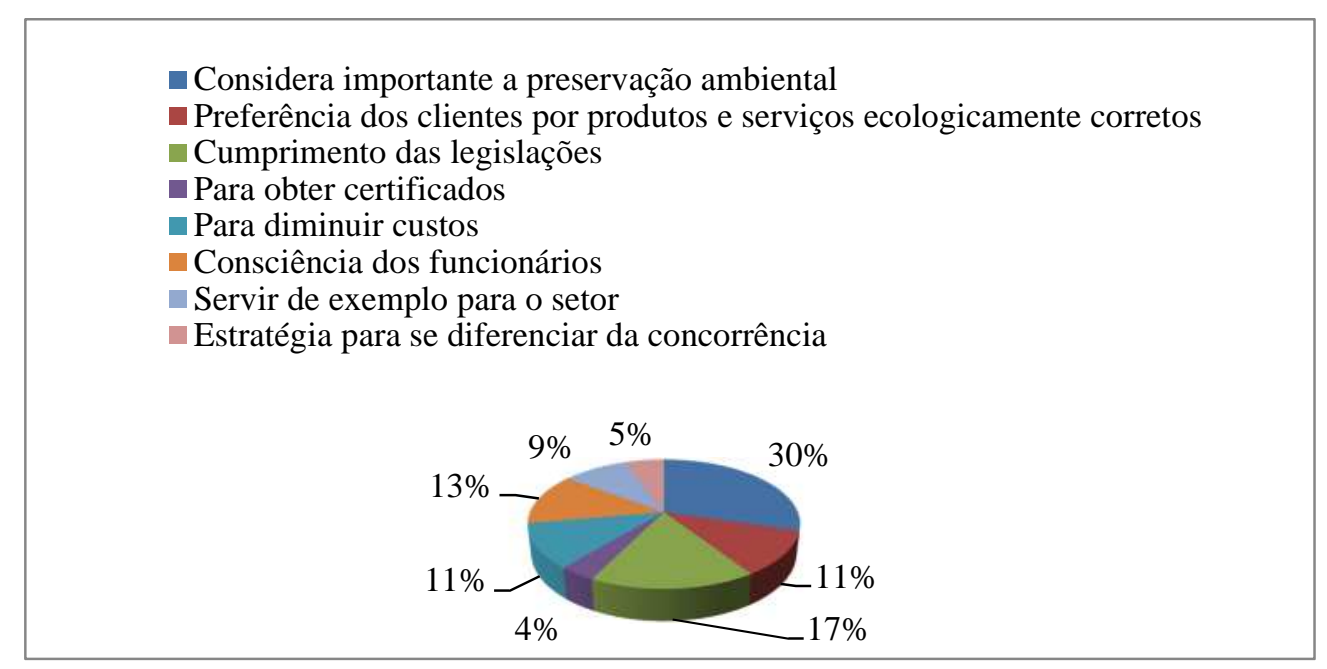

Gráfico 2 - Motivos que levam à prática de ações sustentáveis

Fonte: Elaborado pelas autoras. 2015. 
A maioria das respostas obtidas foi no sentido de considerar importante a preservação ambiental, com índice de 30\%, seguida de $17 \%$ pelo cumprimento das legislações, $13 \%$ pela consciência dos funcionários, $11 \%$ pela preferência dos clientes por produtos e serviços ecologicamente corretos, assim como pelo objetivo de diminuir os custos, também com $11 \%$ das respostas, seguidas da alternativa para servir de exemplo frente ao setor, com $9 \%$, ser uma estratégia para diferenciar-se da concorrência, com 5\% e com objetivo de obtenção de certificados ambientais, com $4 \%$ das respostas.

Através deste resultado foi possível observar que nem todos os gestores estão conscientes da possibilidade de reduzir seus custos e consequentemente aumentar o seu lucro através da execução de ações sustentáveis, que de acordo com Savitz e Weber (2007), é um dos princípios de uma empresa sustentável. Diante da pergunta sobre quem seriam os responsáveis por sugerir, definir ou implantar as ações de sustentabilidade no restaurante, $56 \%$ das respostas indicaram os proprietários como os responsáveis pela sugestão, definição e implantação das ações sustentáveis, seguido pelos gerentes ou gestores com $16 \%$ e pelos clientes, igualmente com $16 \%$, ainda $9 \%$ das respostas indicam que as iniciativas partem dos funcionários e $3 \%$ dos fornecedores.

Os gestores também responderam a pergunta sobre a existência ou não, de algum treinamento para realização de ações sustentáveis. Entre os respondentes do questionário, 72\% afirmaram realizar algum treinamento neste sentido, enquanto $28 \%$ responderam negativamente.

Ainda com relação ao treinamento para a realização de ações sustentáveis, aos que responderam positivamente foi indagado ainda quem seria o responsável por realizar este treinamento. A alternativa que obteve mais respostas foi a que indicava a gerência, com 53\% do total, seguida da observação das práticas cotidianas corretas, com $41 \%$ e através de cursos aplicados fora da empresa, com $6 \%$. As opções que indicavam o treinamento por terceiros contratados especializados no assunto ou por um funcionário do restaurante não obtiveram nenhuma resposta.

Apesar da maior parte dos gestores afirmarem realizar algum tipo de treinamento, estes resultados demonstram que a maioria das iniciativas parte deles próprios, de acordo com sua consciência ambiental ou acabam incorporando-se no dia-a-dia do restaurante através da observação do que seria correto praticar, sem haver um maior interesse na busca por alternativas muitas vezes desconhecidas por eles. 
Os gestores foram questionados se acham que os clientes levam em consideração as ações sustentáveis desenvolvidas pelos restaurantes, a maior parte das respostas obteve afirmação positiva, totalizando $83 \%$, enquanto $17 \%$ acham que os clientes não levam em consideração as ações sustentáveis desenvolvidas pelos restaurantes. As afirmativas positivas estão de acordo com Nascimento (2012) que considera que em decorrência de uma nova consciência proveniente das reações adversas que o uso indiscriminado dos recursos naturais tem causado ao meio ambiente e da atribuição desta responsabilidade, os clientes estão cada vez mais comprometidos com a questão da sustentabilidade e essa busca se faz presente também nos produtos e serviços que consomem.

Os gestores também foram questionados sobre quais seriam os benefícios da realização de ações sustentáveis, sendo suas respostas demonstradas no Gráfico 3.

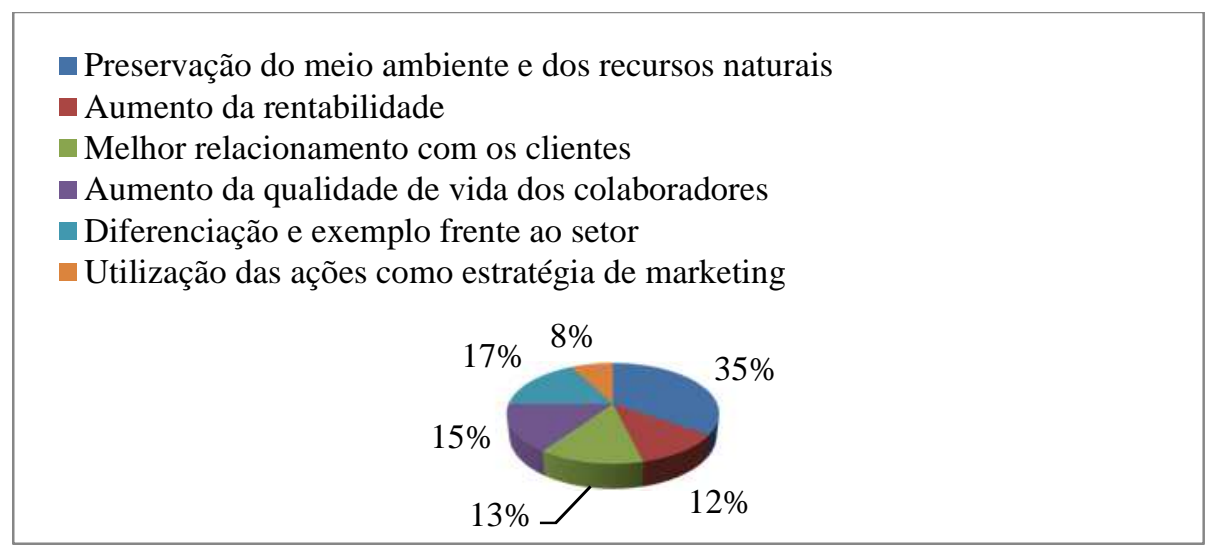

Gráfico 3 - Benefícios de realizar ações sustentáveis

Fonte: Elaborado pelas autoras. 2015.

Dos entrevistados $35 \%$ afirmaram ser a preservação do meio ambiente e dos recursos naturais o principal benefício da realização de tais ações, enquanto $17 \%$ afirmaram ser a possibilidade de diferenciação e de se tornar um exemplo frente ao setor. O aumento da qualidade de vida dos colaboradores foi apontado em $15 \%$ das respostas, o melhor relacionamento com os clientes obteve $13 \%$ enquanto o aumento da rentabilidade $12 \%$ e a utilização das ações como estratégia de marketing $8 \%$ das respostas. Foi demonstrado através deste questionamento, pouco conhecimento com relação ao aumento da rentabilidade reiteradas por Nunes (2012) e Nery et al (2013), pois a redução do desperdício de alimentos e a otimização dos recursos naturais como água e energia já são em si, ações suficientemente capazes de diminuir os custos e aumentar o lucro dos restaurantes. 
O Gráfico 4 demonstra o percentual das respostas de acordo com a pergunta sobre o que tende a dificultar a realização de ações sustentáveis no restaurante.

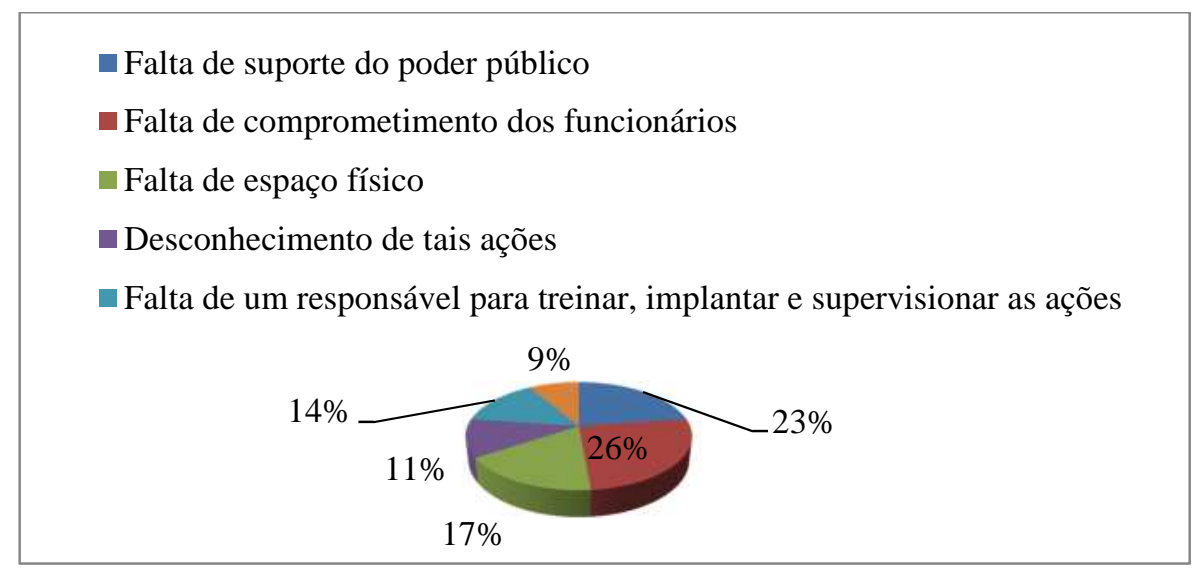

Gráfico 4 - O que dificulta a realização de ações sustentáveis Fonte: Elaborado pelas autoras. 2015.

O maior número de respostas foi obtido através da alternativa que indicava a falta de comprometimento dos funcionários, com índice de $26 \%$, demonstrando uma carência característica do setor, seguido pela falta de suporte do poder público, com $23 \%$, falta de espaço físico, com 17\%, falta de um responsável para treinar, implantar e supervisionar a realização das ações, com 14\%, seguido do desconhecimento de tais ações, com $11 \%$ e da escassez de recursos financeiros, com $9 \%$ das respostas.

Acre e Castilho (2013) em concordância com as questões da falta de comprometimento dos funcionários e da falta de suporte do poder público, principalmente no que diz respeito a falta de incentivo à coleta seletiva, afirmam que estes são os principais desafios encontrados na implantação da gestão ambiental nas empresas do setor de alimentos e bebidas. Consideram ainda, que boa parte das ações exigem um baixo investimento para serem implantadas e podem ser aplicadas pelos próprios gestores, o tempo gasto em treinamento e sensibilização dos colaboradores certamente será revertido através da rentabilidade com a diminuição do desperdício de produtos e recursos naturais, além do provável aumento da produtividade e da qualidade do trabalho através do comprometimento de todos os envolvidos nos processos, que é um fator fundamental para a efetivação das ações sustentáveis.

Os gestores foram também questionados sobre o que facilitaria a implementação de ações sustentáveis no restaurante, as respostas são descritas de acordo com o Gráfico 5. 
- Maior incentivo do poder público

- Parceria com ONG's e outras entidades que dão suporte a tais práticas

- Contato com produtores locais de agricultura familiar

- Acesso a fornecedores comprometidos com a sustentabilidade

- Acesso a cursos e treinamentos para a implantação de tais ações

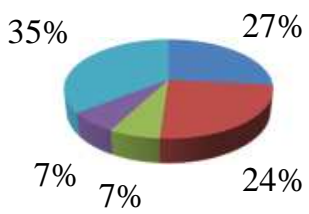

Gráfico 5 - O que facilitaria a implementação de ações sustentáveis Fonte: Elaborado pelas autoras. 2015.

A resposta da maioria dos gestores foi no sentido da necessidade de acesso a cursos e treinamentos para a implementação de tais ações com $35 \%$ das respostas, a alternativa relacionada ao poder público indicou que um maior incentivo por parte do mesmo facilitaria a adoção de ações sustentáveis na visão dos gestores, com um total de $27 \%$ das respostas, seguido por parcerias com organizações não governamentais (ONG's) e outras entidades que dão suporte às práticas sustentáveis, com 24\%, o acesso a fornecedores comprometidos com a sustentabilidade e o contato com produtores locais de agricultura familiar, obtiveram $7 \%$ das respostas cada.

De acordo com as respostas fornecidas através do questionário aplicado aos gestores dos restaurantes buffet, foi possível perceber que de uma forma geral, a maior parte deles demonstra certa preocupação com as questões ambientais que envolvem os processos de suas atividades produtivas e procuram, de uma forma ou de outra, fazer algo para minimizar os impactos. Porém, o setor ainda necessita de uma maior conscientização, principalmente no que diz respeito a questão da reciclagem do lixo, já que a cidade de Florianópolis conta com o apoio do poder público através da coleta seletiva. Apesar de boa parte dos estabelecimentos citarem esta como uma ação realizada ainda é necessário que ela seja mais efetiva, para que isto ocorra, basta que os gestores se organizem, principalmente no sentido de conscientizar seus colaboradores sobre a importância desta questão para que ocorra a correta separação entre os resíduos recicláveis e não recicláveis dentro do restaurante, para que eles sejam armazenados e então dispostos para coleta especializada nos dias específicos de cada bairro, 
informação esta, fornecida pela Companhia de Melhoramentos da Capital (COMCAP), órgão responsável pela coleta seletiva no município.

Outra questão passível de atenção é no que se refere a otimização, tanto dos recursos naturais, quanto das matérias-primas. Através da análise das questões, foi possível identificar que nem todos os gestores tem consciência da importância que a economia de recursos como água e energia tem sobre o meio ambiente, já que atualmente, o perigo de escassez é eminente e a economia pode refletir ainda de maneira positiva na rentabilidade da empresa, o que também se aplica à utilização integral dos alimentos, porcionamento correto das porções e diminuição do desperdício.

O destino ambientalmente adequado do lixo orgânico, questão muito importante por ser o principal resíduo produzido pelos restaurantes, ainda não é uma prática comum entre eles e pode ser considerado um ponto fraco, talvez por exigir maior infraestrutura por parte dos estabelecimentos ou ainda por não contarem com apoio de outras entidades para a realização desta ação, o que demonstrou ser fundamental, como no caso do apoio prestado pela Associação Comercial e Industrial de Florianópolis (ACIF) na coleta e destinação adequada do óleo de cozinha usado, principal ação sustentável realizada pelos restaurantes.

Apesar do questionário apresentar respostas positivas no sentido da realização de ações sustentáveis, considera-se que ainda são necessárias diversas mudanças aliadas a conscientização e educação ambiental para que estes restaurantes possam ser considerados sustentáveis. Vale ressaltar que o fator aumento da rentabilidade pode vir a ser um argumento positivo e de suma importância para que as empresas optem pela sustentabilidade, aliado ainda a ações estratégicas de marketing que podem ser utilizadas para melhorar a imagem da empresa, além de atrair e fidelizar clientes comprometidos com esta questão.

Para que isto ocorra, a necessidade de união dos diversos setores se faz presente, assim como a conscientização ambiental e a adequação à nova realidade com que se deparam. Este seja talvez, o principal desafio enfrentado por eles, já que boa parte dos gestores citou que o acesso a cursos e treinamentos facilitaria a implementação de ações sustentáveis, assim como um maior suporte do poder público e acesso à entidades e ONG's que dão apoio a estas práticas. Neste sentido, a busca por parcerias entre os setores público e privado, além do terceiro setor pode ser a peça chave na busca por uma sociedade mais justa e equilibrada com o meio ambiente. 


\section{Considerações Finais}

Este estudo foi desenvolvido com a finalidade de contextualizar os impactos ambientais causados pelas atividades produtivas das empresas do setor gastronômico, assim como, analisar a percepção dos gestores com relação às 'boas práticas' de sustentabilidade ambiental aplicadas nos restaurantes buffet. Com a realização da pesquisa bibliográfica foi possível elencar diversas ações passíveis de aplicação no setor, ações estas que abrangem a otimização dos recursos naturais, a utilização de energias renováveis envolvendo também aspectos arquitetônicos do local, os processos dos produtos desde o seu cultivo ao seu fornecimento, armazenamento, preparo e distribuição, com destaque para a gestão e correta destinação dos resíduos produzidos através dos processos produtivos.

Através da aplicação do questionário, foi possível perceber a visão dos gestores dos restaurantes da tipologia escolhida para análise deste estudo, apesar deste assunto ainda não ser amplamente divulgado ou abordado com maior afinco entre os estudiosos do setor, de uma forma geral há uma preocupação por parte dos estabelecimentos em diminuir os impactos causados por suas atividades, já que boa parte deles considera a preservação ambiental o principal motivo para a implementação e prática das ações sustentáveis nos restaurantes. Porém, é preciso um maior comprometimento por parte de todos os envolvidos, sejam eles pertencentes ao setor público ou privado, quer estejam desempenhando o papel de gestores, de colaboradores, ou ainda de consumidores já que a degradação do meio ambiente chegou a pontos praticamente irreversíveis e é dele que se obtém as matérias primas essenciais para a execução desta atividade profissional.

Neste sentido, o mercado atual tem exigido cada vez mais que as empresas invistam em questões voltadas para a sustentabilidade e o meio ambiente, inclusive como forma de retorno financeiro, o que já é visto como um diferencial entre as empresas modernas e preocupadas com o futuro. Sendo assim, a sustentabilidade precisa ser encarada como um fator fundamental entre as empresas que buscam equilíbrio econômico, social e ambiental.

Este trabalho propôs a discussão do tema sustentabilidade no meio gastronômico, chamando a atenção para esta questão e indicando alternativas para que cada vez mais as práticas sustentáveis sejam incorporadas à Gastronomia. A relevância deste estudo se deu no sentido de despertar a consciência dos gestores para as diversas ações que podem ser aplicadas nos 
restaurantes, podendo ainda, servir como base para novas pesquisas e auxiliar a implementação de práticas sustentáveis no setor de alimentos e bebidas.

\section{Referências}

ABREU, M. J. Gestão comunitária de resíduos orgânicos: o caso do projeto revolução dos baldinhos (PRB), o capital social e agricultura urbana. 2013. 150 p. Dissertação (Mestrado em Agrossistemas) Centro de Ciências Agrárias, Universidade Federal de Santa Catarina, Florianópolis, 2013.

ACIF, Associação Comercial e Industrial de Florianópolis. Disponível em: <http://www.acif.org.br/index.php/reoleo/historico-programa-reoleo>. Acesso em: 15 out. 2014.

ACRE, D. M.; CASTILHO, F. R. Gestão ambiental aplicada ao setor gastronômico: proposta para Dourados - MS. Revista Rosa dos Ventos, Caxias do Sul, v. 5, n. 2, p. 248-263, abr./jun. 2013.

AMARAL, D. A.; COSTA, J. R. C.; CORRÊA, A. C.; FREITAS, V. A. B. A compostagem como mecanismo de aproveitamento dos resíduos sólidos produzidos em restaurantes e cozinhas industriais no município do Rio Grande - RS. In: IX SIMPÓSIO INTERNACIONAL DE QUALIDADE AMBIENTAL, 2014, Porto Alegre. Anais... Porto Alegre: SIQA, 2014.

AMORIM, M. M. A.; JUNQUEIRA, R. G.; JOKL, L. Adequação nutricional do almoço self-service de uma empresa de Santa Luzia, MG. Revista Nutrição, Campinas, v. 18, n. 1, p. 145-156, jan./fev. 2005.

ANVISA, Agência Nacional de Vigilância Sanitária. Alimentos. Legislação. Regulamento técnico de boas práticas para serviços de alimentação. Disponível em: <http://portal.anvisa.gov.br/wps/wcm/connect/4a3b680040bf8cdd8e5dbf1b0133649b/RESOLU\%C3\% 87\% C3\% 83O-RDC+N+216+DE+15+DE+SETEMBRO+DE+2004.pdf?MOD=AJPERES >. Acesso em: 27 set. 2014.

ARCHANJO, L. R.; BRITO, K. F. W.; SAUERBECK, S. Alimentos orgânicos em Curitiba: consumo e significado. Revista Cadernos de Debate, Campinas, v. 8, p. 1-6, 2001.

BARBOSA, E. M., S.; PRATA, A. P.; SILVA, E. S.; VILAÇA, E. M. Aplicações tecnológicas como fontes renováveis cocção solar em comunidades na região de Xingó. Revista Avances en Energías Renovables y Medio Ambiente, San Miguel, v. 11, 2007a.

BARbOSA, E. M., S.; PRATA, A. P.; SILVA, E. S.; TIBA, C. Avaliação dos benefícios socioeconômicos em aplicações fotovoltaicas com finalidades produtivas - caso restaurante grota de angicos. Revista Avances en Energías Renovables y Medio Ambiente, San Miguel, v. 11, 2007b.

BLICK, A. P.; SILVA, D. L. D.; COSTA, G. A. N.; BENASSI, V. T.; GARCIA, S. Aproveitamento de subprodutos: restaurantes de Londrina, 2008. Disponível em: <http://www.unicesumar.edu.br/pesquisa/periodicos/index.php/rama/article/viewFile/974/71>. Acesso em: 15 set. 2014.

BÔAS, G. F. M. V. Alimentos regionais: avaliação das mudanças da oferta no programa de restaurantes populares brasileiros. 2013. 93 p. Monografia (Pós-Graduação em Nutrição Humana) Faculdade de Ciências da Saúde, Universidade de Brasília, Brasília, 2013.

BOCHNIA, J.; SANTOS, J. T.; SILVA, A. G.; SILVA, C. A. A gestão dos resíduos sólidos gerados no restaurante universitário de uma instituição de ensino superior. Engenharia Ambiental, Espírito Santo do Pinhal, v. 10, n.2, p. 081-089, mar./abr. 2013.

BOOF, L. Sustentabilidade: O que é - O que não é. Petrópolis, RJ: Vozes, 2012. 
BRASIL. Senado Federal. Atividade. Matéria. Disponível em: <http://www.senado.gov.br/atividade/materia/detalhes.asp?p_cod_mate=105088>. Acesso em: 06 out. 2014.

CORAL, E. Modelo de planejamento estratégico para a sustentabilidade empresarial. 2002.282 p. Tese (Doutorado em Engenharia de Produção) - Programa de Pós-graduação em Engenharia de Produção, Universidade Federal de Santa Catarina, Florianópolis, 2002.

COSTA, A. C. R.; PEREIRA, A. B.; CAMELO, G. L. P. Sustentabilidade como estratégia de desenvolvimento: a nova tendência do mercado internacional. In: II CONGRESSO DE PESQUISA E INOVAÇÃO DA REDE NORTE NORDESTE DE EDUCAÇÃO TECNOLÓGICA, 2007, João Pessoa. Anais... João Pessoa: CONNEPI, 2007.

CRISTÓVÃO, A.; TIBÉRIO, M. L. Comprar fresco, comprar local. In: VIII COLÓQUIO IBÉRICO DE ESTUDOS RURAIS, Coimbra, 2008. Anais... Coimbra: CIER, 2008.

DINEGREEN. Green Restaurant Association. Certification standarts. Disponível em: <http://dinegreen.com/restaurants/standards.asp>. Acesso em: 10 set. 2014.

FARIA, D. M.; GASPAROTTO, D. P.; BARBOSA, R. A. T. Estudo sobre a economia de energia no restaurante universitário através do uso de aquecimento solar de água. Revista Ciências do Ambiente, Campinas, v. 1, n. 1, ago. 2005.

FREITAS, C. F.; BARATA, R. A. R.; MOREIRA, L. S. M. Utilização do óleo de cozinha usado como fonte alternativa na produção de energia renovável, buscando reduzir os impactos ambientais. In: XXX ENCONTRO NACIONAL DE ENGENHARIA DE PRODUÇÃO, São Carlos, 2010. Anais... São Carlos: ENENGEP, 2010.

HOPPEN, N.; LAPOINTE, L.; MOREAU, E. Um guia para a avaliação de artigos de pesquisa em sistemas de informação. REAd, v. 22,n.2. p. 1-34, 1996.

KRAUSE, R. W.; BAHLS, Á. A. D. S. M. Orientações gerais para uma gastronomia sustentável. Revista Turismo Visão e Ação, Itajaí, v. 15, n. 3, p. 434-450, set./dez. 2013.

KREMER, E.C.; COSTA, J.I.P.; MONDO, T.S. Análise das ações de responsabilidade ambiental implementadas nos restaurantes do centro de Florianópolis. TURyDES, v.6, n.14. 2013.

LAFUENTE, A. N. A. Resíduos sólidos em um restaurante comercial: um estudo de caso na cidade de Santos/SP. Revista de tecnologia aplicada, Santos, v. 6, n. 2, p. 44-61, mai./ago. 2012.

LOCATELLI, A. F.; SANCHEZ, R. S. S.; ALMEIDA, F. Q. A. A. Redução, reutilização e reciclagem de resíduos em unidade de alimentação e nutrição. Revista Simbio-Logias, v. 1, n. 2, nov. 2008.

MALHOTRA, N. K. Pesquisa de marketing: uma orientação aplicada. 3. ed. Porto Alegre:

Bookman, 2001.

MARINOSKI, D. L.; SALAMONI, I. T.; RÜTHER, R. Pré-dimensionamento de sistema solar fotovoltaico: estudo de caso do edifício sede do CREA-SC. In: I CLACS e X ENTAC, 2004, São Paulo. Anais... São Paulo: CLACS, ENTAC, 2004.

MONFORTE, S. F. Responsabilidade social empresarial e a sustentabilidade na hotelaria. 2007.80 p. Monografia (Pós-graduação Lato-Sensu) - Centro de excelência em Turismo, Universidade de Brasília, Brasília, 2007.

MONTEIRO, R. Z.; CIANCIARDI, G.; BRUNA, G. C. Projeto de retrofit para espaços destinados a serviços de alimentação. In: IV SEMINÁRIO INTERNACIONAL DA LARES - Mercado Imobiliário, 2004, São Paulo. Anais... São Paulo: LARES, 2004.

NASCIMENTO, J. C. Consciência ambiental, hábitos e expectativas de consumidores da feira ecológica de Porto Alegre. 2012, 55 p. Monografia (graduação em Administração) - Universidade Federal do Rio Grande do Sul, Porto Alegre, 2012. 
NERY, C. H. C.; CONTO, S. M.; ZARO, M.; PISTORELlO, J.; PEREIRA, G. S. Geração de resíduos sólidos em eventos gastronômicos: o Festiqueijo de Carlos Barbosa, RS. Revista Rosa dos Ventos, Caxias do Sul, v. 5, n. 2, abr./jun. 2013.

NUNES, Radilene. Gastronomia Sustentável. Interação - Revista Científica da Faculdade das Américas, São Paulo, ano III, n. 1, jan./jul. 2012.

OLIVEIRA, L. H.; GONÇALVES, O. M. Metodologia para a implantação de programa de uso racional da água em edifícios. São Paulo: Escola Politécnica da USP, 1999. (Boletim Técnico, $\mathrm{BT} / \mathrm{PCC} / 247)$.

OLIVEIRA, S. M.; MAGALHÃES, C. S. Restaurante universitário sustentável: análise de um modelo desejado na Universidade Federal de Uberlândia (MG). In: III CONGRESSO BRASILEIRO DE GESTÃO AMBIENTAL, 2012, Goiânia. Anais... Goiânia: CBGA, p. 1-7, 2012.

PERUCHIN, B.; GUIDONI, L. L. C.; CORRÊA, L. B.; CORRÊA, E. K. Gestão de resíduos sólidos em restaurante escola. Revista Tecno-Lógica, Santa Cruz do Sul, v. 17, n. 1, p. 13-23, jan./jun. 2013.

PETRINI, C. Slow Food: princípios da nova gastronomia. São Paulo: Senac São Paulo, 2009.

PINTO, R. A. Projeto e implementação de lâmpadas para iluminação de interiores empregando diodos emissores de luz (LEDS). 2008. 138 p. Dissertação (Mestrado em Engenharia Elétrica) Universidade Federal de Santa Maria, Santa Maria, 2008.

POSPISCHEK, V.S,; SPINELLI, M.G.N.; MATIAS, A. C. G. Avaliação de ações de sustentabilidade ambiental em restaurantes comerciais localizados no município de São Paulo. Demetra, v. 9. n.2. p.595-611. 2014

PUIATTI, E. W.; LAMOUNIER, M. A. T; PÔNCIO, M. G.; GOMIDE, T. G. Gastronomia Sustentável Faz Bem. Belo Horizonte: Senac. Minas Gerais, 2013.

QUEIRÓZ, M. I. de P. O pesquisador, o problema da pesquisa, a escolha de técnicas: algumas reflexões. In: Lang, A.B.S.G., org. Reflexões sobre a pesquisa sociológica. São Paulo, Centro de Estudos Rurais e Urbanos, 1992. p. 13-29. (Coleção Textos; 2a série, 3).

REIS, L. F. S. S. D.; QUEIROZ, S. M. P. Gestão ambiental em pequenas e médias empresas. Rio de Janeiro: Qualitymark, 2002.

RITA, D. O.; AMARANTE, C. J.; SEEMAN, D. K.; SILVA, J. E. O.; SILVA, G. T. Gestão sustentável de restaurantes universitários: o caso de uma Universidade Federal no sul do Brasil. In: XIII COLÓQUIO DE GESTIÓN UNIVERSITÁRIA EN AMÉRICAS, 2012, Florianópolis. Anais... Florianópolis: CGUA, 2012.

RUBIM, R. E. A ecogastronomia nos cursos superiores de gastronomia do estado de São Paulo: conceito, aplicações e cenário observado. Revista Rosa dos Ventos, Caxias do Sul, v. 5, n. 2, p. 280292, abr./jun. 2013.

SANTOS, A. S. F.; AGNELLI, J. A. M.; MANRICH, S. Tendências e desafios da reciclagem de embalagens plásticas. Polímeros: Ciência e Tecnologia, São Carlos, v. 14, n. 5, p. 307-312, 2004.

SANTOS, R. SANTOS, R.; BELO, V. A.; FORMIGONI, A.; RODRIGUES, E. F.; CAMPOS, I. P. A. O processo da gestão de resíduos nas embalagens de pós-consumo: estudo de caso McDonald's. Revista Metropolitana de Sustentabilidade, São Paulo, v. 3, n. 2, p. 99-109, 2013.

SAVITZ, A. W.; WEBER, K. A empresa sustentável: o verdadeiro sucesso é o lucro com responsabilidade social e ambiental. 3. ed. Rio de Janeiro: Elsevier, 2007.

SCHNEIDER, R. C. S.; SANTOS, E.; KLAMT, R. A.; MACHADO, E. L. Gestão do uso de óleos vegetais em restaurante visando a produção mais limpa. In: 2nd INTERNATIONAL WORKSHOP ADVANCES IN CLEANER PRODUCTION, Santa Cruz do Sul, 2009. Anais... Santa Cruz do Sul: IWACP, 2009. p. 1-10. 
SEBRAE. Serviço brasileiro de apoio às micro e pequenas empresas. Disponível em: < http://www.sebrae-sc.com.br/ideais/default.asp?vcdtexto=1356\& $\&^{\wedge \wedge}>$. Acesso em: 06 out. 2014.

SERRÃO, M.; ALMEIDA, A.; CARESTIATO, A. Sustentabilidade: uma questão de todos nós. Rio de Janeiro: Senac Nacional, 2012.

SILVÉRIO, G. A.; OLTRAMARI, K. Desperdício de alimentos em unidades de alimentação e nutrição brasileiras. Ambiência - Revista do Setor de Ciências Agrárias e Ambientais, Guarapuava, v. 10, n. 1, p. 125-133, jan./abr. 2014.

SINGER, P.; MASON, J. A ética na alimentação: como nossos hábitos alimentares influenciam o meio ambiente e o nosso bem-estar. Rio de Janeiro: Elsevier, 2007.

SOllA, J.; SILVA, F. N. M. C. Cadernos de Sustentabilidade da Rio+20: diretrizes de sustentabilidade e guia de boas práticas da organização da Conferência das Nações Unidas sobre Desenvolvimento Sustentável. Brasília: FUNAG, 2012.

SOUZA, Í. M. G.; CARVALHO, L. S. C.; BARTHOLO JÚNIOR, R. S. Mapeamento da agricultura familiar agroecológica do estado do Rio de Janeiro para o abastecimento do restaurante universitário da UFRJ e para promoção do comércio direto. In: $9^{\circ}$ ENCONTRO NACIONAL DE ENGENHARIA E DESENVOLVIMENTO SOCIAL, Natal, 2012. Anais... Natal: ENEDS, 2012.

SOUZA, M. T. S. Organização sustentável: indicadores setoriais dominantes de sustentabilidade análise de um segmento do setor de alimentação. In: XXIV Encontro Anual de Associação Nacional dos Programas de Pós-Graduação e Pesquisa em Administração - ENANPAD. Florianópolis, 2000. Anais... Florianópolis, 2000. v. 1. p. 200-215.

THESRA, The Sustainable Restaurant Association. About us. What are sustainable restaurants. Disponível em: <http://www.thesra.org/about-us/what-is-sustainability/>. Acesso em: 12 set. 2014.

VENZKE, C. S. A geração de resíduos em restaurantes, analisada sob a ótica da produção mais limpa. In: ENCONTRO NACIONAL DE ENGENHARIA DE PRODUÇÃO, 21, Salvador, 2001. Anais... Salvador: ENENGEP, 2001.

ZANELLA, Luis Carlos. Instalação e administração de restaurantes. São Paulo: Metha, 2007.

ZUIN, L. F. S.; ZUIN, P. B. Produção de alimentos tradicionais: contribuindo para o desenvolvimento local/regional e dos pequenos produtores rurais. Revista Brasileira de Gestão e Desenvolvimento Regional, Taubaté, v. 4 , n. 1, p. 109-127, jan./abr. 2008.

\section{Recebido em: 19/06/2015 (1 ${ }^{\text {a }}$ versão) $14 / 10 / 2015$ ( $2^{\mathrm{a}}$ versão)}

Aprovado em: 22/10/2015 